\title{
Development and validation of the Patient-Physician Relationship Scale among patients with irritable bowel syndrome
}

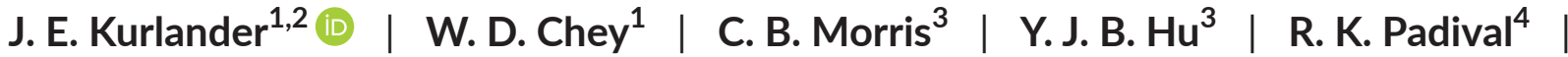 \\ S. I. Bangdiwala ${ }^{5,6}$ | N. J. Norton ${ }^{7}$ | W. F. Norton ${ }^{7}$ | D. A. Drossman ${ }^{3,6}$
}

${ }^{1}$ Department of Internal Medicine, University of Michigan Medical School, Ann Arbor, MI, USA

${ }^{2}$ Veterans Affairs Ann Arbor Health Care System, Ann Arbor, MI, USA

${ }^{3}$ Drossman Center for the Education and Practice of Biopsychosocial Care and Drossman Gastroenterology, Chapel Hill, NC, USA

${ }^{4}$ Department of Internal Medicine, University of lowa Hospitals and Clinics, lowa City, IA, USA

${ }^{5}$ Gillings School of Global Public Health, University of North Carolina, Chapel Hill, NC, USA

${ }^{6}$ UNC Center for Functional GI \& Motility Disorders, University of North Carolina, Chapel Hill, NC, USA

${ }^{7}$ International Foundation for Functional Gastrointestinal Disorders, Milwaukee, WI, USA

Correspondence Jacob Kurlander, Medical Center Dr., SPC 5362, Ann Arbor, MI 48109-5362, USA.

Email: jkurland@umich.edu

Funding information

This study was funded by Ironwood

Pharmaceuticals.

\begin{abstract}
Background: An effective patient-physician relationship (PPR) is essential to the care of patients with irritable bowel syndrome (IBS). We sought to develop and validate an IBS-specific instrument to measure expectations of the PPR.

Methods: We conducted structured focus groups about PPRs with 12 patients with IBS. Qualitative analysis was used to generate a questionnaire (the Patient-Physician Relationship Scale [PPRS]), which was modified with input from content experts and usability testing. For validation, we administered it online to US adults with IBS. Participants also completed the Functional Bowel Disorder Severity Index, the Rome III Adult Functional gastrointestinal (GI) Disorder Criteria Questionnaire, and modified versions of the Communication Assessment Tool (CAT-15) and Patient-Doctor Relationship Questionnaire (PDRQ-9). We performed principal components factor analysis for the PPRS.

Key Results: The PPRS contained 32 questions with responses on a 7-item Likert scale. Themes included interpersonal features, clinical care expectations, and aspects of communication. One thousand and fifty-four eligible individuals completed the survey (88\% completion rate). Most participants were middle aged (mean 48 years, SD $16.3)$, white (90\%), and female (86\%). Factor analysis showed only one relevant factor, relating to quality of PPR. The final scale ranged from possible-96 to +96 (mean 62.0, SD 37.6). It correlated moderately with the CAT-15 $(r=.40, P<.001)$ and PDRQ-9 $(r=.30, P<.001)$, establishing concurrent validity.

Conclusions \& Inferences: We describe the development and validation of the first questionnaire for use in measuring patient expectations of the PPR, which can be used for future outcomes studies and training physicians.
\end{abstract}

KEYWORDS

irritable bowel syndrome, patient-physician relationship, survey

\section{1 | INTRODUCTION}

Patients with irritable bowel syndrome (IBS) are commonly encountered in clinical practice, ${ }^{1}$ but many physicians view them as challenging to treat. ${ }^{2,3}$ Many patients with IBS also feel that interactions with their physicians fall short of their expectations, ${ }^{4}$ contributing to an overall sense of frustration. ${ }^{5}$ One reason for sometimes strained relationships between gastroenterologists and patients with IBS is that they often have discordant views of the nature and severity of gastrointestinal symptoms, ${ }^{6}$ and many patients with IBS may fail to 
acknowledge that they have the condition at all. ${ }^{7}$ In fact some clinicians may not acknowledge IBS or consider it a less important condition than "organic" diseases like inflammatory bowel disease or celiac disease, both of which cause similar symptoms to IBS, but are accompanied by more objective endoscopic, structural, or histological findings. $^{6}$

Employing strategies to form a more effective and collaborative patient-physician relationship (PPR) is advocated as one of the most important and therapeutic strategies in the treatment of IBS. ${ }^{8}$ The basis of this relationship is mutual acceptance of the reality of the disorder and patient trust that the clinician understands and wants to help. Patients with IBS may value the relational aspect of their medical care as highly as they do the technical aspects. ${ }^{9}$ The PPR is not only a desirable end in itself but is also an important mediator of other therapeutic outcomes. In general, interventions to improve either patient or physician communication have demonstrated improvements in satisfaction with care, treatment adherence, emotional health, symptom resolution, daily function, and physiologic measures (eg, blood pressure). ${ }^{10}$ The PPR may be particularly important to outcomes in patients with IBS, ${ }^{11}$ in which interventions to improve the PPR have resulted in improvements in symptomatology. ${ }^{12}$ The quality of the PPR in IBS is thought to be one of the most significant predictors of long-term prognosis. ${ }^{13}$

Given the importance of the PPR, it is essential to have an accurate understanding of IBS patients' expectations of the relationship. Yet, few existing research instruments are well suited to this task. Instruments that have been developed for use in broader (non-IBS) populations suffer many theoretical shortcomings. They mainly assess the physician's perception of how patients conform to (physician) expectations. For example, the physician-rated Difficult Doctor Patient Relationship Questionnaire ${ }^{14}$ queries the extent to which patients are frustrating or self-destructive. This may contribute to the tendency to focus unproductively on "difficult" or "problem" patients, ${ }^{15-17}$ when in fact these are difficult encounters that are understood to be a shared responsibility of patient and physician. ${ }^{18}$

For the patient, validated survey instruments exist to measure trust in the physician (Trust in Physician Scale ${ }^{19}$ ), shared perspective with the physician (Physician-Patient Concordance Scale ${ }^{20}$ ), and overall quality of the therapeutic alliance (Patient-Doctor Relationship Questionnaire $\left.[\mathrm{PDRQ}]^{21}\right)$. However, none of these has been validated among patients with IBS or attend to the specific disease-specific concerns of IBS patients. By and large, research into the PPRs has suffered from a lack of attention to their longitudinal nature, relationships under stress, and care provided by subspecialists, all of which apply to IBS. $^{22}$ Here we report for the first time the development of a psychometrically validated instrument to quantify IBS patients' expectations of their physicians with regard to the PPR.

\section{2 | METHODS}

\section{1 | Item creation}

To generate a complete list of provider and relationship factors associated with the quality of the PPR, we conducted structured focus

\section{Key Points}

- An effective patient-physician relationship (PPR) is essential to treating IBS.

- We describe the development and validation of a scale of patient expectations for IBS.

- This instrument may be used for clinical research and educating trainees.

groups with a convenience sample of patients who had previously been diagnosed with IBS and treated in the Gastroenterology Clinic at the University of Michigan, and had agreed to participate in research studies. Patients who were followed in clinic by any of the study investigators were excluded. Participants were remunerated a \$10 Target gift card, and \$20 cash. A total of 12 patients participated in three focus groups. Mean age was 42 years (range 1958). Nine were female and three were male. Nine participants were white and three were African-American. Six patients had IBS-D and six had IBS-C.

Focus groups were conducted using standard methods previously used by the investigators in instrument development. ${ }^{23}$ Facilitators asked predetermined questions to elicit positive and negative aspects of the PPR, with follow-up questions based on responses. Qualitative analysis included note-taking during meetings, post-meeting debriefing by facilitators and note takers, and review of recordings. Using these strategies, a complete list of themes identified during the focus groups was generated. Questions that were not related to either qualities of the provider or the relationship were excluded, for example, courtesy of clerical staff.

Using the items elicited in the focus groups, we created a preliminary questionnaire (the Patient-Physician Relationship Scale [PPRS]). The prompt queried participants about the "ideal provider caring for my gastrointestinal symptoms," and contained 32 items (Appendix 1). Response options were on a 7-item Likert scale anchored by "very undesirable" and "very desirable." Questions were worded both positively and negatively to avoid systematic responses in the favorable direction. To ensure clarity and completeness of the questions, the instrument was reviewed by having a convenience sample of 10 patients, 10 gastroenterologists and GI fellows, and 6 content experts, provide feedback on whether the items were clear, understandable, redundant and/or unnecessary, and whether they had any suggestions for clarification or additional topics. Modifications were made to the instruments based on this feedback.

\section{2 | Validation}

The survey instrument was administered online using Qualtrics survey software (Qualtrics, Provo, UT, USA). A link to the survey was posted on the website of the International Foundation for Functional Gastrointestinal Disorders (www.iffgd.org and www.aboutibs.org). 
An online invitation directing patients to the survey was posted on November 17, 2014, the first day of survey collection. The survey was closed on Sept 28, 2015. Participants were offered the opportunity to win one of thirty $\$ 100$ gift cards that would be allocated by raffle. Inclusion criteria were age $\geq 18$ years, residence in the United States, reporting a previous diagnosis of IBS by a physician, and having seen a medical provider for their gastrointestinal symptoms at least once in the previous 6 months. All individuals who accessed the survey were directed to provide answers to these questions, and to additional questions about demographics and disease characteristics. Only patients who responded affirmatively to questions about inclusion criteria were allowed to take the remainder of the survey. Respondents could return to the website on a later occasion to complete the survey.

\section{3 | Instruments}

Participants completed the Functional Bowel Disorder Severity Index $(\text { FBDSI })^{24}$ and the Rome III Adult Functional GI Disorder Criteria Questionnaire for IBS, ${ }^{25}$ including subtype, to evaluate whether they met strict criteria for IBS.

Participants were also administered two additional modified versions of previously developed survey instruments. One was the Communication Assessment Tool (CAT-15), a measure of patients' perception of physicians' communication skills. ${ }^{26}$ This instrument, used here to establish concurrent validity, was initially developed for use by patients evaluating their own personal physicians. However, because we were interested in the importance of the concepts in general, we modified the original Likert scale of the CAT-15 for our study purposes to "not at all important" to "extremely important" from the original scale, which ranged from poor to excellent. The wording of several questions was also modified and a question about clinic staff was removed.

The second instrument was the Patient-Doctor Relationship Questionnaire (PDRQ-9), a measure of the therapeutic aspects of the patient-doctor relationship developed for use in general clinical practice. ${ }^{21}$ Since this scale was also designed to be administered in reference to a patient's personal physician, we again modified the scale to range from "not at all important" to "extremely important" and the questions were reworded to query what is important for a gastroenterologist to do instead of what is done in an actual clinic visit. The wording for question 5 was also modified to "be dedicated to help me" from "be dedicated to me."

\subsection{Analysis}

Descriptive statistics were generated for patient demographics, disease characteristics, and the previously validated scales. We performed principal components factor analysis on the responses to the PPRS. We evaluated the association of demographic and disease characteristics with scores on the PPRS using $t$ tests and ANOVA. We evaluated correlations between the PPRS and the modified CAT-15 and PDRQ-9 using Pearson correlations. All analyses were performed using SAS statistical software (SAS Institute Inc. Cary, NC, USA).

\section{5 | Ethics}

This study was reviewed and found to be exempt by the University of Michigan Institutional Review Board.

\section{3 | RESULTS}

A total of 3742 surveys were initiated over the 10-month assessment period. Seventy-seven responses were identified as duplicates (eg, identical email addresses, identical IP addresses completed within $<2$ hours of each other or with identical date of birth) and removed from the dataset, leaving 3665 unique surveys that were initiated. Two thousand four hundred and sixty-eight surveys were excluded because of ineligibility ( 555 did not respond to any of the eligibility questions, 100 had age <18, 1010 lived outside the United States, 471 had not been diagnosed by a physician with IBS, while the remainder were ineligible based on $>1$ criterion that were missing or disqualifying). Of the 1197 surveys that were started and met eligibility criteria, 1054 were completed (88.1\%) and included in the final analysis.

\section{1 | Respondents}

The sample was characterized as middle aged (mean age 48.0, SD 16.3), White (90.2\%), predominantly female (86.2\%), and $86.6 \%$ met Rome criteria for IBS. The severity of their IBS was mostly moderate $(46.1 \%)$ or severe $(41.9 \%)$. This was reflected in their work status. $19.3 \%$ were not working due to their health and another $19.8 \%$ were not working for other reasons. $76.1 \%$ had been to see the physician at least twice over the last year. Almost $70 \%$ had restricted their activities at least 10 days/month.

When we compared those who completed the survey to those who did not complete the survey, we found completers appeared to have more severe illness as they more often restricted their usual activities (53.1 vs 39.6 days, $P<.05$ ), and had significantly more major surgeries ( 3.3 vs $2.8, P<.04$ ). Completers also tended to have seen their gastroenterologists more often in the prior 6 months (3.2 times vs 2.8 times, $P<.06)$. There were no other differences in demographic or disease characteristics.

\section{2 | Factor analysis}

Initial factor analysis revealed two principal factors with eigenvalues $>1$. However, review of the responses revealed that all of the positively worded questions loaded on Factor 1 while all of the negatively worded questions loaded on Factor 2 (Table 2). The questions loading on Factor 2 did not otherwise appear to be thematically distinct from questions loading on Factor 1 . We therefore concluded that the two factors reflected the structure of the questions rather than any grouping of conceptually similar items, and that the scale contained only a single clinically relevant factor. To generate the final scale, the negatively worded questions, which loaded in factor 2 , were reverse coded and summed with the questions from factor 1 . No item reduction was 
TABLE 1 Participant characteristics and association with PatientPhysician Relationship Scale (PPRS) score

\begin{tabular}{|c|c|c|c|c|c|c|c|}
\hline \multirow{2}{*}{\multicolumn{4}{|c|}{ Physician Relationship Scale (PPRS) score }} & \multirow[b]{3}{*}{ Variable } & \multirow{3}{*}{ N (\%) } & \multirow{3}{*}{$\begin{array}{l}\text { PPRS score; } \\
\text { Mean (SD) }\end{array}$} & \multirow[b]{3}{*}{$P$-value } \\
\hline & & & & & & & \\
\hline \multirow[b]{2}{*}{ Variable } & \multirow[b]{2}{*}{$N(\%)$} & \multirow{2}{*}{$\begin{array}{l}\text { PPRS score; } \\
\text { Mean (SD) }\end{array}$} & \multirow[b]{2}{*}{$P$-value } & & & & \\
\hline & & & & \multicolumn{4}{|c|}{ Days restricted per month } \\
\hline Male & $145(13.8 \%)$ & $56.9(37.3)$ & .07 & $10-30$ & 415 (39.4\%) & $62.3(37.9)$ & \multirow{2}{*}{$<.05$} \\
\hline Age & & & & $31+$ & $320(30.4 \%)$ & $63.4(37.7)$ & \\
\hline $36-54$ & $373(35.4 \%)$ & $61.2(38.9)$ & \multirow{2}{*}{.001} & Mild & $126(12.0 \%)$ & $65.3(31.8)$ & \multirow[t]{3}{*}{.04} \\
\hline$>54$ & 402 (38.1\%) & $58.2(38.4)$ & & Moderate & 485 (46.1\%) & $64.3(35.2)$ & \\
\hline Education & & & & Severe & $442(41.9 \%)$ & $58.6(41.4)$ & \\
\hline HS or less & $143(13.6 \%)$ & $45.1(44.0)$ & \multirow[t]{2}{*}{$<.001$} & Rome IBS Dia & & & \\
\hline Any college & $625(59.3 \%)$ & $63.0(37.5)$ & & No & $141(13.4 \%)$ & $59.7(38.7)$ & NS \\
\hline Black & $44(4.2 \%)$ & $51.3(48.7)$ & \multirow{3}{*}{ NS } & IBS-M & $566(62.0 \%)$ & $62.7(35.9)$ & \multirow{3}{*}{ NS } \\
\hline Hispanic & 54 (5.1\%) & $53.9(44.5)$ & & IBS-C & 100 (11.0\%) & $59.0(42.1)$ & \\
\hline Declined & $5(0.5 \%)$ & $46.3(52.2)$ & & IBS-U & $4(0.4 \%)$ & $80.8(12.4)$ & \\
\hline
\end{tabular}

Marital status

Single, never married

$200(19.0 \%)$

$64.9(37.8)$

NS

Married, no

$135(12.8 \%)$

children

Married, with

$457(43.4 \%)$ children

Divorced

$131(12.4 \%)$

$61.7(38.1)$

Separated

$14(1.3 \%)$

51.6 (37.3)

Widowed

39 (3.7\%)

$47.3(44.1)$

Living with

$71(6.7 \%)$

$66.7(37.1)$

partner

$7(0.7 \%)$

$64.9(40.0)$

$\begin{array}{llll}\begin{array}{l}\text { Employment status } \\ \text { Working or in } \\ \text { school }\end{array} & 642(60.9 \%) & 65.5(34.6) & .003 \\ \begin{array}{l}\text { Not working or in } \\ \text { school because } \\ \text { of health } \\ \text { problems }\end{array} & 203(19.3 \%) & 59.2(40.3) & \\ \begin{array}{l}\text { Not working or in } \\ \text { school for other } \\ \text { reasons }\end{array} & 209(19.8 \%) & 54.1(42.3) & \\ \begin{array}{l}\text { Household income } \\ \text { Less than }\end{array} & 615(58.3 \%) & 60.1(39.2) & <.05 \\ \begin{array}{l}\$ 75 \text { 000 } \\ \text { More than }\end{array} & 439(41.7 \%) & 64.7(35.1) & \\ \$ 74999 & & & \\ \text { Physician visits } & & & \\ 0-1 & 252(23.9 \%) & 63.1(33.6) & \text { NS } \\ 2-4 & 535(50.8 \%) & 61.2(38.6) \\ 5+ & 267(25.3 \%) & 62.8(41.9) & \end{array}$

(Continues)
TABLE 1 (Continued)

${ }^{a}$ FBDSI data was missing for one patient because of technical error.

${ }^{\mathrm{b}}$ Includes only patients with irritable bowel syndrome (IBS) diagnosis by Rome criteria.

performed because all questions loaded on factor 1 or factor 2 with a loading $>0.60$. The final scale had a possible range from -96 to +96 after reverse coding for negative items, where a higher score indicated greater expectations of the PPR. The mean score was 62.0 (SD 37.6).

\subsection{Association of patient characteristics with PPRS scores}

Table 1 displays the mean PPRS score for clinical variables under evaluation. Several patient characteristics correlated with a higher score on the PPRS. These included younger age ( $P=.001)$, higher educational attainment $(P<.001)$, male gender (borderline at $P=.07)$, fewer days restricted from activities $(P<.05)$, working status $(P=.003)$, FBDSI

Scores on the PPRS had moderate correlation with responses to the CAT-15 $(r=.40, P<.001)$ and PDRQ-9 $(r=.30, P<.001)$.

\section{4 | DISCUSSION}

An effective PPR is the foundation upon which effective treatment for IBS rests. ${ }^{8,27}$ However, patient expectations of their providers often fall short of their actual experiences ${ }^{4}$ and, relative to the significant ongoing investments into the development of novel diagnostic and pharmacologic strategies for IBS, there has been relatively little investigation of ways to improve the PPR. One impediment to this area of research may be the dearth of disease-specific research instruments to measure what IBS patients want from their providers. $(P=.04)$, and household income $>\$ 74999(P<.05)$ (Table 1). 
TAB LE 2 Factor loadings for questions included in the Patient Provider Relationship Scale

\begin{tabular}{|c|c|c|}
\hline $\begin{array}{l}\text { The ideal provider caring for my gastroin- } \\
\text { testinal symptoms }\end{array}$ & Factor 1 & Factor 2 \\
\hline 1. Listens to me & 0.82 & 0.30 \\
\hline 2. Provides educational information & 0.78 & 0.32 \\
\hline 3. Will continue to care for me & 0.83 & 0.23 \\
\hline 4. Spends adequate time with me & 0.83 & 0.27 \\
\hline 5. Fails to give me treatment options & 0.08 & 0.73 \\
\hline $\begin{array}{l}\text { 6. Makes decisions about my care without } \\
\text { involving me }\end{array}$ & 0.19 & 0.75 \\
\hline 7. Is someone I respect & 0.85 & 0.15 \\
\hline 8. Is empathic and caring & 0.85 & 0.19 \\
\hline 9. Does not do a physical examination & 0.05 & 0.61 \\
\hline 10. Is someone I can trust & 0.90 & 0.22 \\
\hline 11. Checks to make sure I understand & 0.87 & 0.21 \\
\hline $\begin{array}{l}\text { 12. Makes me feel comfortable when } \\
\text { talking about my GI problems }\end{array}$ & 0.85 & 0.22 \\
\hline 13. Interrupts me & 0.15 & 0.72 \\
\hline 14. Is someone I like & 0.81 & 0.02 \\
\hline 15. Is someone I feel connected to & 0.81 & 0.03 \\
\hline 16. Uses language I understand & 0.75 & 0.10 \\
\hline 17. Accepts my feelings and point of view & 0.88 & 0.16 \\
\hline $\begin{array}{l}\text { 18. Refers me to other providers when } \\
\text { needed }\end{array}$ & 0.79 & 0.26 \\
\hline 19. Can be humorous & 0.70 & 0.00 \\
\hline 20. Is knowledgeable & 0.82 & 0.26 \\
\hline 21. Does not explain my condition to me & 0.18 & 0.79 \\
\hline 22. Comes up with a plan of care & 0.84 & 0.27 \\
\hline 23. Knows about my case & 0.87 & 0.24 \\
\hline 24. Makes it easy for me to understand & 0.84 & 0.19 \\
\hline 25. Is rude & 0.32 & 0.73 \\
\hline $\begin{array}{l}\text { 26. Is responsive to my questions and } \\
\text { concerns }\end{array}$ & 0.89 & 0.22 \\
\hline 27. Is available to me & 0.81 & 0.27 \\
\hline 28. Is dismissive & 0.18 & 0.80 \\
\hline 29. Is friendly & 0.80 & 0.07 \\
\hline 30. Seems rushed & 0.18 & 0.77 \\
\hline 31. Is not concerned about me & 0.14 & 0.79 \\
\hline 32. Is honest & 0.87 & 0.22 \\
\hline
\end{tabular}

In this study, we found that patients have multiple expectations of their providers and that these fit into certain clinically meaningful domains. These relate to (i) interpersonal features, including trust, respect, honesty, empathy, humor, likeability and creating a sense of connectedness, (ii) clinical care expectations, including being knowledgeable, performing a physical exam, providing patient education, collaborating with other providers, spending adequate time with the patient, and providing a plan of care; and finally, (iii) communication aspects of the PPR, including not interrupting, not being rude, allowing the patient to feel heard, speaking in an understandable manner and creating a sense of comfort when the patient is talking about problems. These attributes, often expressed by patients, harmonize with and support the values taught by clinicians and investigators who espouse the value of the PPR. ${ }^{8,28}$ Of note, when patients rate their expectations of the physician caring for their IBS, the factor analysis revealed a single factor despite there being conceptually different domains, with items similarly weighted, and with the second eigenvalue quite small in comparison to the first. The single factor takes into consideration the differences in how the patients as a group responded to negatively worded questions. The identified values of this questionnaire were also seen to have concurrent validity with other research instruments in which (non-IBS) patients assess doctors' communication and relational traits.

While several previous research instruments have been developed to measure the socioemotional qualities of an individual patientphysician interaction, this is the first instrument to focus exclusively on (IBS) patient expectations of the ideal provider. This distinguishes our instrument from the Irritable Bowel Syndrome Satisfaction with Care Scale (IBS-SAT), which includes a subset of questions on provider connection and education, but also themes such symptom relief, the office environment, and access ${ }^{29}$; the CAT-15, which allows patients to measure multiple providers' (physicians' and others') visit-specific interpersonal and communication skills ${ }^{26}$; the Patient-Doctor Relationship Questionnaire (PDRQ-9), developed in the Netherlands and intended for use among primary care patients, focusing mostly on the helping attitude of the doctor, to the exclusion topics such as physician education style ${ }^{21}$; or the Patient Reactions Assessment, developed among patients seen at a cancer center, with three subscales related to information, affect, and communication. ${ }^{30}$ Our instrument should also be distinguished from broader measures of patients' satisfaction with medical care, such as the Patient Satisfaction Questionnaire (PSQ-III), which includes domains such as the technical aspects of care, access, and finances. ${ }^{31}$

Our instrument is also set apart from previous instruments by including items specifically addressing the expectations and distinctive concerns of patients with IBS, which is marked by a heterogeneous clinical phenotype, nebulous etiology, and lack of objective diagnostic biomarkers. For example, Halpert, et al., found that IBS patients frequently endorsed expectations relating to information provision, communication skills (provision of support and hope), and responsiveness to questions. ${ }^{4}$ In a separate study, Halpert, et al., found that patients highly valued physicians who spent sufficient time, had better listening skills, and used a shared decision-making model. ${ }^{11}$ In another study of the expressive writing of US patients with IBS, content analysis showed that providing education and empathy were the most important factors for an effective PPR. ${ }^{32}$ Finally, a qualitative study of 51 patients with IBS in the United Kingdom and Netherlands found that patients expected some form of confirmatory testing for their IBS diagnosis, ${ }^{33}$ in keeping with other studies showing that many IBS patients may feel that their illness is not validated by the healthcare system. ${ }^{5}$ Generally, our survey instrument included almost all of the domains found to be important in these previous studies. While the 
importance of confirmatory testing, found in a previous study, was not a theme found in our focus groups, this may relate to the fact that the European study was conducted among primary care patients, while the focus group participants in our study were drawn from patients seen in a Gl clinic.

The results of this study have important implications for clinical practice and medical training. This instrument could be used to classify patients according to their level of expectations of their physicians, opening up the possibility for new lines of investigation about how expectations affect outcomes. The items in the survey can be used to gauge the performance characteristics of physicians based on patient expectations, as a means of evaluation. It can also help to train physicians in patient-physician listening and communication in IBS, which is one of the most common gastrointestinal disorders seen in both primary care and specialty practice. Finally, this survey can be used in the future to develop additional survey instruments to evaluate the quality of individual PPRs among IBS patients. We plan to compare this instrument to one under development that assesses physician expectations in the PPR and then test their validity in matched assessment of patients and their providers. These validated instruments can then be used to gauge the effectiveness of the PPR and to provide a basis for training to improve clinical skills in this area of patient care. Other important areas for future study include evaluating the PPRS's test-retest reliability, and its association with outcomes such as patient satisfaction, health-related quality of life, health care utilization, and treatment response.

Our results underscore the importance of the PPR in clinical care. We believe that sustained attention to the PPR in IBS can yield multiple dividends. An improved PPR can ameliorate symptoms and quality of life in irritable bowel syndrome, ${ }^{12}$ decrease risk of malpractice claims, ${ }^{34}$ and may even make clinical care for "challenging" patients more rewarding. However, clinicians face substantial financial pressure to increase patient "throughput" and to prioritize procedures over return clinic visits. We hope our survey will help make clear to policy makers the importance of face-to-face time with patients, and help clinicians to prioritize what matters most to patients during limited time together.

This study has a number of strengths since the questions were developed through a rigorous multi-step process that has been previously used for instrument development. Furthermore, it was validated among a large nationwide sample of IBS patients in the United States. Its limitations include sampling bias for the Internet-based validation sample, since patients with Internet access may not be representative of the broader population of patients with IBS (eg, age, severity, income), and self-selected participants may be systematically different than non-participants ("the volunteer effect"). ${ }^{35}$ It appears that those with seemingly more severe illness completed the survey. White patients may have also been over-represented. An important area for future research will be further validation of our survey instrument in a sample representative of patients with IBS.

In conclusion, we have developed a psychometrically valid PPR scale that can be used to assess the level of expectations that patients with IBS have of their providers.

\section{ACKNOWLEDGMENTS}

We thank Drs. Albena Halpert, Lucinda Harris, Kurt Kroenke, Susan Lucak, Dennis Novack, and Brennan Spiegel for their input as content experts in the development of this questionnaire. All consented to acknowledgment.

\section{AUTHOR CONTRIBUTION}

JEK, DAD and WDC designed the research study and wrote the paper; NJN and WFN provided access to patient sample; JBH contributed to data entry; JBH, CM and SIB analyzed the data; SIB, JEK, DAD, WDC and RP interpreted the results. All authors were involved in critical revisions of the manuscript.

\section{DISCLOSURE}

The authors have no competing interests.

\section{REFERENCES}

1. Peery AF, Crockett SD, Barritt AS, et al. Burden of gastrointestinal, liver, and pancreatic diseases in the United States. Gastroenterology. 2015;149:1731-1741, e3. https://doi.org/10.1053/j.gastro.2015. 08.045 .

2. Drossman DA. Challenges in the physician-patient relationship: feeling "drained". Gastroenterology. 2001;121:1037-1038.

3. Dixon-Woods M, Critchley S. Medical and lay views of irritable bowel syndrome. Fam Pract. 2000;17:108-113.

4. Halpert A, Dalton CB, Palsson O, et al. Irritable bowel syndrome patients' ideal expectations and recent experiences with healthcare providers: a national survey. Dig Dis Sci. 2010;55:375-383. https://doi. org/10.1007/s10620-009-0855-8.

5. Bertram S, Kurland M, Lydick E, Locke GR, Yawn BP. The patient's perspective of irritable bowel syndrome. J Fam Pract. 2001;50: 521-525.

6. Dalton CB, Drossman DA, Hathaway JM, Bangdiwala SI. Perceptions of physicians and patients with organic and functional gastrointestinal diagnoses. Clin Gastroenterol Hepatol. 2004;2:121-126.

7. Collins J, Farrall E, Turnbull DA, Hetzel DJ, Holtmann G, Andrews JM. Do we know what patients want? The doctor-patient communication gap in functional gastrointestinal disorders. Clin Gastroenterol Hepatol. 2009;7:1252-1254, e2. https://doi.org/10.1016/j.cgh.2009.06.025.

8. Drossman DA. 2012 David sun lecture: helping your patient by helping yourself-How to improve the patient-physician relationship by optimizing communication skills. Am J Gastroenterol. 2013. http:// www.nature.com.proxy.lib.umich.edu/ajg/journal/vaop/ncurrent/ full/ajg201356a.html. Accessed November 19, 2013.

9. Halpert A. Irritable bowel syndrome: what do patients really want? Curr Gastroenterol Rep. 2011;13:331-335. https://doi.org/10.1007/ s11894-011-0205-9.

10. Stewart MA. Effective physician-patient communication and health outcomes: a review. Can Med Assoc J. 1995;152:1423-1433.

11. Halpert AD, Thomas AC, Hu Y, Morris CB, Bangdiwala SI, Drossman DA. A survey on patient educational needs in irritable bowel syndrome and attitudes toward participation in clinical research. J Clin Gastroenterol. 2006;40:37.

12. Conboy LA, Macklin E, Kelley J, Kokkotou E, Lembo A, Kaptchuk T. Which patients improve: characteristics increasing sensitivity to a supportive patient-practitioner relationship. Soc Sci Med 1982. 2010;70:479-484. https://doi.org/10.1016/j.socscimed.2009.10.024. 
13. Owens DM, Nelson DK, Talley NJ. The irritable bowel syndrome: long-term prognosis and the physician-patient interaction. Ann Intern Med. 1995;122:107-112. https://doi.org/10.1059/ 0003-4819-122-2-199501150-00005.

14. Hahn SR, Thompson KS, Wills TA, Stern V, Budner NS. The difficult doctor-patient relationship: somatization, personality and psychopathology. J Clin Epidemiol. 1994;47:647-657. https://doi. org/10.1016/0895-4356(94)90212-7.

15. Gerrard TJ, Riddell JD. Difficult patients: black holes and secrets. BMJ. 1988;297:530-532. https://doi.org/10.1136/bmj.297.6647.530.

16. Hahn SR, Kroenke K, Spitzer RL, et al. The difficult patient. J Gen Intern Med. 1996;11:1-8.

17. Drossman DA. The problem patient: evaluation and care of medical patients with psychosocial disturbances. Ann Intern Med. 1978;88:366-372.

18. An PG, Rabatin JS, Manwell LB, Linzer M, Brown RL, Schwartz MD. Burden of difficult encounters in primary care: data from the minimizing error, maximizing outcomes study. Arch Intern Med. 2009;169:410.

19. Anderson LA, Dedrick RF. Development of the Trust in Physician scale: a measure to assess interpersonal trust in patient-physician relationships. Psychol Rep. 1990;67:1091.

20. Kerse N, Buetow S, Mainous AG, Young G, Coster G, Arroll B. Physician-patient relationship and medication compliance: a primary care investigation. Ann Fam Med. 2004;2:455-461.

21. Van der Feltz-Cornelis C. A patient-doctor relationship questionnaire (PDRQ-9) in primary care: development and psychometric evaluation. Gen Hosp Psychiatry. 2004;26:115-120. https://doi.org/10.1016/j. genhosppsych.2003.08.010.

22. Roter $\mathrm{D}$. The enduring and evolving nature of the patient-physician relationship. Patient Educ Couns. 2000;39:5-15.

23. Drossman DA, Chang L, Schneck S, Blackman C, Norton WF, Norton NJ. A focus group assessment of patient perspectives on irritable bowel syndrome and illness severity. Dig Dis Sci. 2009;54: 1532-1541.

24. Drossman DA, Li Z, Toner BB, et al. Functional bowel disorders. A multicenter comparison of health status and development of illness severity index. Dig Dis Sci. 1995;40:986-995.

25. Drossman D. Rome III: The Functional Gastrointestinal Disorder, 3rd ed. Mclean, VA, USA: Degnon Associates Inc; 2006.

26. Makoul G, Krupat E, Chang $\mathrm{CH}$. Measuring patient views of physician communication skills: development and testing of the communication assessment tool. Patient Educ Couns. 2007;67:333-342.

27. Shen B, Soffer E. The challenge of irritable bowel syndrome. Cleve Clin J Med. 2001;68:224-236.

28. Levinson W, Lesser CS, Epstein RM. Developing physician communication skills for patient-centered care. Health Aff (Millwood). 2010;29:1310-1318. https://doi.org/10.1377/hlthaff.2009.0450.

29. Dorn SD, Morris CB, Schneck SE, et al. Development and validation of the irritable bowel syndrome satisfaction with care scale. Clin Gastroenterol Hepatol. 2011;9:1065-1071, e2. https://doi. org/10.1016/j.cgh.2011.08.009.

30. Galassi JP, Schanberg R, Ware WB. The patient reactions assessment a brief measure of the quality of the patient-provider medical relationship. Psychol Assess. 1992;4:346-351.

31. Ware JE, Snyder MK, Wright WR. Development and Validation of Scales to Measure Patient Satisfaction with Medical Care Services, Vol I, Part A: Review of Literature, Overview of Methods and Results Regarding Construction of Scales (NTIS Publication No. PB 288-329). Springfield, VA: National Technical Information Service; 1976.

32. Halpert A, Godena E. Irritable bowel syndrome patients' perspectives on their relationships with healthcare providers. Scand J Gastroenterol. 2011;46:823-830. https://doi.org/10.3109/00365521.2011.574729.

33. Casiday RE, Hungin APS, Cornford CS, de Wit NJ, Blell MT. Patients' explanatory models for irritable bowel syndrome: symptoms and treatment more important than explaining aetiology. Fam Pract. 2009;26:40-47. https://doi.org/10.1093/fampra/cmn087.

34. Levinson W, Roter DL, Mullooly JP, Dull VT, Frankel RM. Physician-patient communication. The relationship with malpractice claims among primary care physicians and surgeons. JAMA. 1997;277:553-559.

35. Eysenbach G, Wyatt J. Using the internet for surveys and health research. J Med Internet Res. 2002;4:e13. https://doi.org/10.2196/ jmir.4.2.e13.

How to cite this article: Kurlander JE, Chey WD, Morris CB, et al. Development and validation of the Patient-Physician

Relationship Scale among patients with irritable bowel syndrome. Neurogastroenterol Motil. 2017;29:e13106. https://doi.org/10.1111/nmo.13106

\section{APPENDIX 1}

\section{The Patient-Physician Relationship Scale-Patient Version}

We are interested in understanding the factors that affect patients' relationships with providers who care for their gastrointestinal symptoms. These providers could be primary care providers, gastroenterologists, physician's assistants, or others. Please rate the following factors according to how desirable they are, in your view, in a patientprovider relationship with a provider caring for your gastrointestinal symptoms. Next to each statement, please check the box corresponding to the desirability of the factor, from -3 (very undesirable) to +3 (very desirable). Please note, we are asking your view of how desirable each item is when seeing any provider who cares for gastrointestinal symptoms; we are not asking you to rate a particular provider you have already seen.

The ideal provider caring for my gastrointestinal symptoms:

1. Listens to me

2. Provides educational information

3. Will continue to care for me

4. Spends adequate time with me

5. Fails to give me treatment options

6. Makes decisions about my care without involving me

7. Is someone I respect

8. Is empathic and caring

9. Does not do a physical examination

10. Is someone I can trust

11. Checks to make sure I understand

12. Makes me feel comfortable when talking about my GI problems

13. Interrupts me

14. Is someone I like

15. Is someone I feel connected to

16. Uses language I understand

17. Accepts my feelings and point of view

18. Refers me to other providers when needed

19. Can be humorous

20. Is knowledgeable

21. Does not explain my condition to me

22. Comes up with a plan of care 
23. Knows about my case

24. Makes it easy for me to understand

25. Is rude

26. Is responsive to my questions and concerns

27. Is available to me
28. Is dismissive

29. Is friendly

30. Seems rushed

31. Is not concerned about me

32. Is honest 